\title{
CHILDREN WITH VISION IMPAIRMENT AND MULTIPLE DISABILITIES: ISSUES OF COMMUNICATION SKILLS AND PROFESSIONALS' CHALLENGES
}

\author{
Vassilis Argyropoulos ${ }^{1}$, Charikleia Kanari ${ }^{1}$, Andrea Hathazi ${ }^{2}$ Maria Kyriacou ${ }^{3}$, \\ Maria Papazafiri ${ }^{1}$, \& Magda Nikolaraizi ${ }^{1}$ \\ ${ }^{1}$ Department of Special Education, University of Thessaly (Greece) \\ ${ }^{2}$ Special Education Department, Faculty of Psychology and Educational Sciences, \\ Babes-Bolyai University, Cluj-Napoca (Romania) \\ ${ }^{3}$ St. Barnabas School for the Blind, Nicosia (Cyprus)
}

\begin{abstract}
People with vision impairment and multiple disabilities (MDVI) constitute a population with an enormous heterogeneity due to the combination of various disabilities. Education of children with MDVI concerns different domains and it is considered one of the most demanding fields in Special Education as each student with MDVI has different needs and entails unique educational challenges. In specific, the development of communication skills of children with MDVI is a fundamental domain of their education which affects their learning and active participation in all sectors of life. As a result, professionals are very concerned in which way they can design and develop effective intervention programmes, in order to assess accurately children's communication levels and in turn set realistic goals to consolidate and advance them. The present paper refers to an Erasmus+ project entitled "Promoting effective communication for Individuals with a Vision Impairment and Multiple Disabilities" (PrECIVIM) which acknowledges the need to train teachers in this field and bridges assessment and intervention for the development of communication skills for children with MDVI. The authors present and describe in this paper the following: a. the structure and the content of a training manual for the enhancement of teachers' and professionals' competences in communication skills of children with MDVI, and b. the training process, based on the developed training manual, in three countries (Greece, Cyprus and Romania) in different educational settings for children with MDVI. The obtained data regarding teachers' and professionals' feedback from the training process and their corresponding intervention programmes, revealed a range of good practices as well as concerns and challenges confirming the need of more focused training programmes regarding the education of children with MDVI. The authors conclude that the implementation of intervention programmes, when it comes to communication and levels of communication, depends significantly by a number of factors such as diagnosis, early intervention, system of support for professionals and families, assessment, teachers and professionals' competences, effective use of technology, alternative and augmentative communication, environment, and so on. Finally, it is argued that the aforementioned issues, should be an integral part of a systematic educational policy for the provision of educational opportunities in terms of equality and inclusion for all children including children with MDVI.
\end{abstract}

Keywords: Children with vision impairment and multiple disabilities, communication skills, teachers' training.

\section{Introduction}

Global measures of the number of children with MDVI vary between $30 \%$ and $70 \%$ of the overall population of persons with vision impairments (Kyriacou, Pronay, \& Hathazi, 2015). However, despite the growing numbers of people who are diagnosed with MDVI, there are limited case studies or projects available regarding this population. During the past three decades, there has been a dramatic increase in the number of persons with vision impairments and additional disabilities (MDVI) within the general population of persons with vision impairments (Argyropoulos \& Gentle, 2019).

Children with vision impairment and multiple disabilities (MDVI), may present developmental delays in conjunction with learning difficulties in all areas and levels of perception, cognition and functioning. Hence, it is reasonably to presume that all these delays would have a negative impact on their cognitive, visual, communication and language skills, gross and fine motor skills, daily living as well as social-emotional skills. Nevertheless, amongst all the above difficulties that children with MDVI face, 
the issue of an effective communication seems to be one of the biggest ones because it constitutes a critical bridge between children and their educators or caregivers. For this reason, professionals are very concerned regarding communication issues because the vast majority of all intervention programs are based on communication and aim to consolidate and advance children's communicative competences (Chen \& Downing, 2006; Dammeyer \& Ask Larsen, 2016).

The present paper refers to an Erasmus+ project entitled "Promoting effective communication for Individuals with a Vision Impairment and Multiple Disabilities - PrECIVIM", which aims to support professionals in respect of their intervention programs towards communication and children's communicative competencies (http://precivim.eu/index.php, see also Table 1, the members of the PrECIVIM project). The current project acknowledges the need to train teachers regarding how to assess and teach communication skills to children with MDVI. On the other hand, assessing communicative skills in children with MDVI is a big challenge because communication is a complex domain with many sensory and cognitive sectors which need to be assessed. Receptive and expressive skills as well as sensory and motor skills are related to communication and as a result accurate and systematic assessment procedures are needed. The role of parents is always a critical factor in the process of structured and unstructured observations and constitute an important source of information for teachers to set realistic goals, develop appropriate learning exercises and address the educational needs of children with MDVI (Bruce, Luckner, \& Ferrell, 2018; Hathazi, 2014).

In line with the above needs and within the context of the PrECIVIM project, a training material was designed and developed in order to enhance teachers' and professionals' competences in communication skills of children with MDVI, and in turn training events followed in different educational settings for children with MDVI accompanied with corresponding intervention programs (i. e. the implementation phase of the PrECIVIM project).

\section{Design, objectives and outputs}

All members of the PrECIVIM consortium decided upon the design and activities pertinent to the production of the training material -it was the $3^{\text {rd }}$ intellectual output of the PrECIVIM project - as well as the structure of the training events. Of course there was a work plan from the beginning but details were decided during the project meetings which took place in the first year of the project.

\subsection{Training material}

The leading organization of the training material was the Babeş-Bolyai University (BBU) and all members of the project contributed according to the agreed work plan of the project (see Table 1).

Table 1. Project Tasks regarding design and development of the training material.

\begin{tabular}{|c|c|c|c|}
\hline $\begin{array}{l}\text { Intellectual } \\
\text { Outputs (IO) }\end{array}$ & Project Tasks (T) & $\begin{array}{l}\text { Activity Leading } \\
\text { Organisation }\end{array}$ & Participating Organisations \\
\hline $\begin{array}{l}\text { IO3: Training } \\
\text { Material - } \\
\text { Design and } \\
\text { Content }\end{array}$ & $\begin{array}{l}\text { T3.1 Creation and adaptation } \\
\text { of training material into the } \\
\text { format of a syllabus } \\
\text { framework } \\
\text { T3.2 Creation of consultative } \\
\text { workshops relevant to the } \\
\text { training material } \\
\text { T3.3 Creation of learning } \\
\text { exercise formats }\end{array}$ & $\begin{array}{l}\text { UNIVERSITATEA } \\
\text { BABES BOLYAI }\end{array}$ & 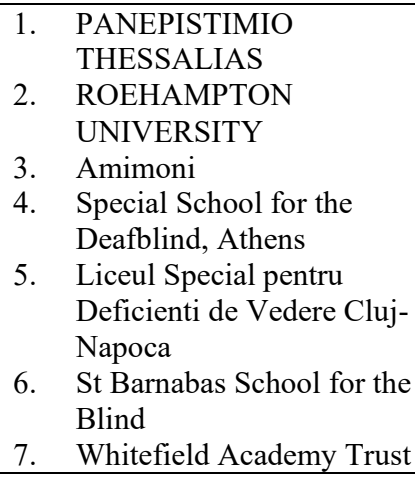 \\
\hline
\end{tabular}

Three modules composed the training material and its framework was based on the concept of bridging theory and practice; that is to say, that the training manual included many theoretical information with practical examples of case studies, activities, assessment methodologies, intervention programs, which were provided by specialists from schools and institutions of the project consortium (see also Table 1). According to the leading organization (BBU), the objectives of the training manual were: a. to get familiarized with updated literature review, b. to understand the implications of visual impairment and multiple disabilities on development, communication and learning, c. to have a hand-on experience with proposed activities and methodologies, d. to develop assessment according to the needs of individuals with visual impairment and multiple disabilities, e. to develop and use instructional materials to support the specific needs of individuals with visual impairment and multiple disabilities, and $\mathrm{f}$. to invite trainees to self-reflective and self-evaluation procedures. 
The modules of the training manual are considered as complementary sources which converged to an enriched resource for specialists in order to learn and extend on their knowledge regarding the population of children with MDVI as well as to provide them an opportunity to carry out practical activities and exercises that would improve working skills regarding evaluation and intervention. The components of the training manual are presented in brief in Table 2:

Table 2. The three modules of the PrECIVIM training manual.

\begin{tabular}{|c|c|}
\hline Modules & Description \\
\hline \multirow{7}{*}{$\begin{array}{l}\text { Conceptual Framework of } \\
\text { development and characteristics } \\
\text { people with MDVI }\end{array}$} & Defining MDVI \\
\hline & Typology of disabilities in the population with MDVI \\
\hline & Characteristics of people with MDVI and implications for \\
\hline & development \\
\hline & Development of communication in the context of MDVI \\
\hline & Development of communication \\
\hline & Assessment and reflections \\
\hline \multirow{12}{*}{$\begin{array}{l}\text { Development of communication in } \\
\text { the context of MDVI }\end{array}$} & Goals and objectives of assessment \\
\hline & Types of assessment \\
\hline & Standardized assessment \\
\hline & Developmental assessment \\
\hline & The educational assessment \\
\hline & Functional or ecological assessment \\
\hline & Observation- assessment tool \\
\hline & Initial observation within the assessment of communication \\
\hline & Inventory on the student's repertoire \\
\hline & Selection of assessment tool \\
\hline & Assessment Plan \\
\hline & Assessment Instruments of communication \\
\hline \multirow{18}{*}{ Assessment of communication } & Milieu approach in developing communication \\
\hline & Routine based interventions \\
\hline & Co-creative communication: method of intervention in \\
\hline & Alternative and augmentative communication \\
\hline & Examples AAC how to select an item from the AAC system \\
\hline & Intervention program for the implementing of an AAC \\
\hline & system \\
\hline & The objects of reference \\
\hline & Symbolic communication strategies \\
\hline & Developing symbolic communication through calendars \\
\hline & Pictures as communication symbols \\
\hline & Picture Exchange Communication System (PECS) \\
\hline & Sign language \\
\hline & The SCERTS Model (Social Communication, Emotional \\
\hline & Regulation and Transactional Support) \\
\hline & Speech development \\
\hline & Communication environment \\
\hline & $\begin{array}{l}\text { Assistive technologies and individuals with visual } \\
\text { impairments and multiple disabilities }\end{array}$ \\
\hline
\end{tabular}

\subsection{Training roadmap and intervention programs}

After the development of the training manual, a combined training scheme took place in nine schools and organizations which were selected by the members of the consortium. The schools were from different countries (i. e. Romania, Cyprus, Greece and the U.K.) and the training scheme, was a combination of two modalities; that is, distance and face-to-face learning events (Souza, Mattos, Stein, Rosário, \& Magalhães, 2018). In specific, the face-to-face learning events was characterized as training on the go. That is to say, the face-to-face trainings took place while the schools were in operation and the teachers were working with their classes. As a result, the trainers were present during classes, they were involved during the intervention programs and after that, trainers and trainees, met and work together through presentations and workshops focusing on their students' real needs using observations and field notes, trying to discuss specific points that would improve or enhance teaching and intervention procedures. During all these processes, the training manual was used as a reference point and the trainers invited the trainees to work out selected parts of it which were relevant to their intervention programs. Hence, the trainers had the opportunity to meet many teachers within a school day individually and usually by the end of the day a plenary session took place. In this way, trainers and trainees had the chance to recap and plan the next steps. 
Apart from the face-to-face training events, distance training events took place which functioned as supplementary material to the overall objectives of the project training phase (asynchronous learning events). The implementation phase (i. e. intervention programs) lasted approximately six months. Teachers, during the implementation phase, filled in reflective logs through which they were thinking critically regarding their experiences and challenges while applying screening inventories of the communicative profile of their students with MDVI.

The present paper, based on obtained data from teachers' and professionals' feedback during the combined training schemes and corresponding intervention programmes in three countries (Greece, Cyprus and Romania), revealed a range of good practices in conjunction with concerns and challenges. All teachers' and professionals' concerns seemed to converge in four domains: a. characteristics of MDVI and levels of communication, b. vision impairment and appropriate environmental adaptations, c. components of tactile perception and touch defensiveness, and $\mathrm{d}$. assessment tools. The trainees acknowledged their lack of training and experience on the previous domains and asked to focus mainly on assessment tools in order to design more effective intervention programs. One of the tools that trainers and trainees worked out elaborately was the Communication Matrix (Rowland \& Fried-Oken, 2010) which they managed to use it, through their intervention programs in order to evaluate their students' expressive communication skills in great detail.

In addition, good practices were considered all procedures which incorporated robust steps from a child's detailed communication profile up to a well-structured intervention program. An example of a good practice with its components is outlined in Table 3.

Table 3. Components of a good practice of the PrECIVIM project.

\begin{tabular}{ll}
\hline Components & Description \\
\hline \multirow{3}{*}{ Input regarding student's communication profile } & $\begin{array}{l}\text { Defining MDVI } \\
\text { Typology of disabilities } \\
\text { Characteristics } \\
\text { Communication level }\end{array}$ \\
\hline \multirow{3}{*}{$\begin{array}{l}\text { Input regarding professionals' plan of their } \\
\text { intervention }\end{array}$} & $\begin{array}{l}\text { Goals and objectives of assessment } \\
\text { Selection of assessment tool } \\
\text { Prioritizing needs }\end{array}$ \\
& Assessment \& Intervention Plan \\
\hline \multirow{3}{*}{ Actions that were conducted during the intervention } & PECs \\
& $\begin{array}{l}\text { Books } \\
\text { Objects of reference }\end{array}$ \\
& $\begin{array}{l}\text { Hands-on activities } \\
\text { social stories }\end{array}$ \\
& $\begin{array}{l}\text { Millieu Approach } \\
\text { routines based on imitations } \\
\text { games }\end{array}$ \\
\hline \multirow{2}{*}{ Professionals' observations during intervention } & Diary \\
& Checklists \\
& $\begin{array}{l}\text { Discussions with the working team } \\
\text { Assessment activities } \\
\text { Children's products }\end{array}$ \\
\hline \multirow{2}{*}{ Professionals' reflection on the results of the } & Was the implementation successful? \\
implementation & Are we going to use the same assessment tool? \\
& Are we going to use the same approaches and strategies? \\
\hline
\end{tabular}

\section{Discussion and conclusions}

It is acknowledged that the development of communication skills differs greatly between children with multiple disabilities and vision impairment (MDVI) and children with typical development (Chen, 1999). Children with MDVI cannot exploit adequately the information derived from the environment (McInnes \& Treffry, 1982). As a result, they need systematic instruction, scaffolding and facilitation. Most of the children who participated in the PrECIVIM project were at pre-intentional communication level regarding the model of development of communication (Rowland \& Fried-Oken, 2010). They tried to communicate through a variety of behaviors such as: crying, fussing, smiling, body movements, and other nonverbal behaviors showing comfort or discomfort (Brady, Steeples, \& Fleming, 2005). The communicative behaviors of children with MDVI at this level of communication, due to limitations of the ability to communicate in meaningful and functional way, may be unusual and therefore sometimes is difficult to identify and interpret them (Ayyildiz, Akcin, \& Guven, 2016).

Before teachers and professionals implement intervention programs aiming at the development of communication skills, it is necessary to evaluate children's preverbal communication with appropriate 
assessment methods (Westling \& Fox 2004). The assessment of children with MDVI communication skills is quite challenging regarding the combination of disabilities (Bruce, Godbold \& Naponelli-Gold, 2004). There is a variety of assessment tools for assessment of communication, ranging from the formal methods such as standardized and non-standardized tests and scales to informal ones (Warner \& Wolf Nelson, 2004).

The PrECIVIM project highlights the added value of the development of partnerships between different organizations, collaborations between different specialists, and systematic evaluation of relevant activities in order to develop knowledge and good practices for equal educational and social opportunities for all children including children with MDVI.

\section{Acknowledgements}

The present project entitled "Promoting effective communication for Individuals with a Vision Impairment and Multiple Disabilities - PrECIVIM (No: 2017-1-EL01-KA201-036289) is funded by the Erasmus+ programme of the European Union and coordinated by the State Scholarships Foundation (IKY).

\section{References}

Argyropoulos, V., \& Gentle, F. (2019). Formal and non-formal education for individuals with vision impairment or multiple disabilities and vision impairment. In J. Ravenscroft (Ed.) The Routledge Handbook of Visual Impairment (pp. 118-142). Abingdon: Routledge.

Ayyildiz, E., Akçin, N., \& Güven, Y. (2016). Development of preverbal communication skills scale for children with multiple disabilities and visual impairment. Journal of Human Sciences, 13(2), 2668-2681.

Bruce, S. M., Godbold, E., \& Naponelli-Gold, S. (2004). An analysis of communicative functions of teachers and their students who are congenitally deafblind. RE:view, 36(2), 81-90.

Bruce, S.M., Luckner, J.L., \& Ferrell, K.A. (2018). Assessment of students with sensory disabilities: evidence-based practices. Assessment for Effective Intervention, 43(2), 79-89.

Chen, D. (1999). Learning to communicate: strategies for developing communication with infants whose multiple disabilities include visual impairment and hearing loss. reSources, 10(5), 1-10.

Chen, D., \& Downing, J. (2006). Strategies for children who have visual impairments and multiple disabilities. New York: American Foundation for the Blind.

Dammeyer, J., \& Ask Larsen, F. (2016). Communication and language profiles of children with congenital deafblindness. British Journal of Visual Impairment, 34(3), 214-224.

Hathazi, A. (2014). Interaction - based intervention programs in multiple disabilities. International Journal of Humanities and Social Science, 4(12), 135-139.

Kyriacou, M., Pronay, B., \& Hathazi, A. (2015). Report of the mapping exercise carried out by the commission of persons with visual impairment and additional disabilities. EBU document. Retrieved from http://www.icevi-europe.org/files/2015/additional-disabilities.pdf

McInnes, J.M., \& Treffry, J.A, (1982). Deafblind infants and children. Toronto: University of Toronto Press.

Rowland, C., \& Fried-Oken, M. (2010). Communication Matrix: A clinical and research assessment tool targeting children with severe communication disorders. Journal of Pediatric Rehabilitation Medicine: An Interdisciplinary Approach, 3, 319-329.

Rowland, C., \& Schweigert, P. (2000). Seven levels of communicative competence. In Communication development and teaching strategies for children with severe and multiple disabilities: Presymbolic communication and tangible symbol systems. Portland: Oregon Health and Science University Design to Learn Projects.

Souza, C. L. E., Mattos, L. B., Stein, A. T., Rosário, P., \& Magalhães, C. R. (2018). Face-to-face and distance education modalities in the training of healthcare professionals: a quasi-experimental study. Frontiers in Psychology, 9(1557), 1-9.

Warner, C., \& Wolf Nelson, N. (2000). Assessment of communication, language, and speech. In B.A. Bracken (Ed.), The psychoeducational assessment of preschool children (3rd ed. pp.145-185). Boston: Allyn \& Bacon.

Westling, D. L., \& Fox, L. (2004). Teaching students with severe disabilities (3rd ed.). New Jersey: Merrill Prentice Hall. 